Revista Eletrônica do Mestrado em Educação Ambienta1

Revista do PPGEA/FURG-RS

ISSN $1517-1256$

Programa de Pós-Graduação em Educação Ambiental

\title{
A centralidade da Educação Ambiental no Projeto Pedagógico Institucional do Instituto Federal de Educação, Ciência e Tecnologia da Bahia - IFBA
}

\author{
Maria Emília dos Santos Gonçalves ${ }^{1}$ \\ ORCID: https://0000-0002-5876-0147 \\ Instituto Federal de ciência e Tecnologia da Bahia \\ Damián Sánchez Sánchez ${ }^{2}$ \\ ORCID: https://0000-0002-4210-2123 \\ Universidade Federal do Espírito Santo
}

\begin{abstract}
Resumo: Trata-se de um estudo com abordagem qualitativa com o objetivo de "Compreender a concepção de Educação Ambiental contida no PPI-IFBA. Para tanto foi realizada Análise Documental em todo o corpo do documento, tendo como base Bardin (2009) a partir dos descritores Educação Ambiental e Meio Ambiente por meio de leitura preliminar, exploração, inferência, interpretação e compreensão da realidade. Constatamos que a apesar do IFBA se comprometer para a formação omnilateral, no que tange à Educação Ambiental, ela se encontra de forma muito tímida e conservadora e sem uma proposta clara para sua efetivação, refletindo desse modo, a concepção do IFBA de Meio Ambiente como recurso para ser poupado, sem questionar as bases de poder no modo de produção de bens, no qual homem e natureza se tomam mercadorias. Palavras-chave: Educação Ambiental; Meio Ambiente; Formação.
\end{abstract}

\section{La centralidad de la Educación Ambiental en el Proyecto Pedagógico Institucional del}

\section{Instituto Federal de Educación, Ciencia y Tecnología - IFBA}

Resumen: Este es un estudio cualitativo con el objetivo de "Comprender la concepción de Educación Ambiental contenida en el PPI-IFBA. Para esto, se realizó un Análisis de Documentos en todo el cuerpo del documento, basado en Bardin (2009) a partir de los descriptores Educación Ambiental y Medio Ambiente a través de lectura preliminar, exploración, inferencia, interpretación y comprensión de la realidad. Observamos que a pesar del hecho de que IFBA se compromete a la

\footnotetext{
${ }^{1}$ Bacharelado em Enfermagem, especialização em educação e mestranda em Gestão social, desenvolvimento regional e educação. Professora do IFBA-Eunápolis. e-mail: emiliasam.ifba@gmail.com

${ }^{2}$ Doutor e Mestre em Educação pela Universidade Federal do Espírito Santo (UFES), na linha de pesquisa: Cultura, Currículo e Formação de Educadores; Graduado em Pedagogia pela Universidade Federal do Espírito Santo. Professor da UFES. e-mail: damian.sanchez@ufes.br
} 
formación omnilateral, con respecto a la Educación Ambiental, es muy tímido y conservador y sin una propuesta clara para su implementación, lo que refleja la concepción de Medio Ambiente de IFBA como recurso para ser ahorrado, sin cuestionar las bases del poder en el modo de producción de bienes, en el que el hombre y la naturaleza se convierten en mercancías.

Palabras clave: Educación Ambiental; Medio ambiente; Formación

\title{
The Centrality of Environmental Education in the Institutional Pedagogical Project of the Federal Institute of Education, Science and Technology - IFBA
}

\begin{abstract}
This is a qualitative study with the objective of "Understanding the conception of Environmental Education contained in the PPI-IFBA. For this, a Document Analysis was performed throughout the body of the document, based on Bardin (2009) from the descriptors Environmental Education and Environment through preliminary reading, exploration, inference, interpretation and understanding of reality. We note that despite the fact that IFBA commits itself to the omnilateral formation, with regard to Environmental Education, it is very shy and conservative and without a clear proposal for its implementation, thus reflecting IFBA's conception of Environment as resource to be spared, without questioning the bases of power in the mode of production of goods, in which man and nature become commodities.
\end{abstract}

Keywords: Environmental Education; Environment; Formation

\section{Introdução}

Nos dias atuais, nos chama atenção o posicionamento de países como os Estados Unidos e o Brasil que minimizam a crise ambiental e atacam as Políticas públicas ambientais, negando o efeito da emissão do $\mathrm{CO}_{2}$, do aquecimento global e a consequente mudança climática que provoca aumento da temperatura, grandes volumes de chuvas, acentuada seca e a desertificação, como resultado do impacto ambiental. $\mathrm{O}$ desenvolvimento econômico e tecnológico e a produção de bens de consumo ainda requerem o uso de recursos naturais, repercutindo no meio ambiente, na qualidade de vida das pessoas e modificando a relação do homem com a natureza, nos levando a questionar se a Terra suportará intensa e contínua agressão, pois passamos do modo de produção para o modo de destruição do planeta como nos disse Gadotti (2005).

Somado a esse cenário se encontra a desigualdade social, decorrente do desenvolvimento econômico também desigual, vitimando a população mais pobre que é, a mais afetada pelas as intempéries da natureza e do desequilíbrio ambiental. Desse modo, precisamos pensar em uma relação mais igualitária entre homem-natureza e homemhomem, considerando o meio ambiente em sua totalidade e o homem inserido nele, superando o crescimento econômico a qualquer custo, para um pensamento voltado ao Desenvolvimento Sustentável, que não se preocupe apenas em poupar recursos naturais para as gerações futuras, mas que permita as pessoas serem sujeitos de direito.

Rev. Eletrônica Mestr. Educ. Ambient. Rio Grande, v. 37, n. 3, p. 162-183, mai./ago. 2020. 
Dessa forma, a Educação Ambiental (EA) se torna importante para a tomada de consciência e a modificação da relação devastadora do homem com a natureza, considerando que os problemas ambientais são também decorrentes das relações sociais desiguais e possibilitando nova visão de mundo, evidenciando a opressão da natureza e do homem, as relações de poder na sociedade e que possa promover a mobilização para o enfrentamento das questões socioambientais.

Daí a importância da Educação na perspectiva interdisciplinar e transversal, superando a fragmentação dos saberes para uma formação crítica-reflexiva, a intervenção na degradação ambiental e para uma concepção ampliada de meio ambiente, considerando a realidade local, pois, como nos alerta Gadotti ao apontar que podemos destruir toda a vida na Terra, “[...] não por efeito de armas nucleares, mas pelo descontrole da produção industrial" (GADOTTI, 2005, p. 15). Assim, a nossa existência dependerá de como iremos conter o modo de destruição ambiental, a nossa relação com o planeta e a construção de sociedades sustentáveis, sobretudo em tempos de governos de direita e extrema-direita, que minimizam o problema socioambiental e acentuam o fosso da desigualdade.

Neste sentido, o espaço escolar se torna fundamental para a E.A, pois a escola tem como função o saber sistematizado e a produção do conhecimento elaborado, científico e metódico (Saviani 1982). A E.A como dimensão da Educação geral, traz em si as tensões de uma sociedade dividida em classes, com interesses diferentes e contraditórios e que muitas vezes não são expressos nas Práticas Pedagógicas da escola, dos docentes ou do educador ambiental, sendo imprescindível a formação dos sujeitos para a transformação social e da relação do homem com a natureza.

Nessa perspectiva, a cidade de Eunápolis que surgiu sob a base do desmatamento da Mata Atlântica para a construção da atual BR 101, para a agricultura e agropecuária e da silvicultura para a produção de celulose que desencadeou impacto socioambiental, se torna importante um projeto de Educação ambiental que possa contribuir para formação de sujeitos atuantes, não apenas na preservação, conservação e recuperação ambiental, mas capazes de intervir na sociedade para uma relação socioambiental mais justa. Assim, o IFBA se torna um espaço privilegiado para a formação em Educação Ambiental, por ser uma instituição pública, por contar com professores graduados, especialistas, mestres e doutores, por sua estrutura física de excelência, por ter condições para desenvolver pesquisa e extensão e por ser responsável pela formação humana e profissional do jovem.

O IFBA assume como missão, “[...] Promover a formação do cidadão históricocrítico, oferecendo ensino, pesquisa e extensão com qualidade socialmente referenciada, 
objetivando o Desenvolvimento Sustentável do país" (PPI-IFBA, 2013, p. 30), buscando, o desenvolvimento do ser humano, com valores éticos, sociais e políticos. Com esta proposta, o projeto de Educação do Instituto está embasado nas proposições teóricas e filosóficas do Materialismo Histórico-Dialético de Marx e Engels, as quais a transformação social é fruto dos conflitos entre os interesses das classes sociais, determinando a condição histórica do indivíduo. O Instituto propõe desse modo, uma Educação que traga a importância do trabalho na construção da sociedade e a análise crítica para a intervenção na sociedade. Uma escola que puxa para si essa missão precisa se comprometer com a sociedade à sua volta, quebrando os muros e deixando de ser uma ilha. O IFBA-Campus Eunápolis precisa conhecer, refletir e agir sobre as questões socioambientais por meio de Práticas Pedagógicas que reproduzam a nobre missão a qual se propôs. Ao apontar a Pedagogia Histórico-crítica como norte para a inserção da prática educativa, o Instituto toma a Educação como prática social, na qual o educando conhece a realidade e nela intervém efetivamente.

Neste sentido, este estudo busca compreender a concepção de E.A contida no Projeto Político Pedagógico Institucional do IFBA (PPI-IFBA) como instituição de ensino voltada à formação humana omnilateral. Para tanto, a investigação foi realizada a partir da análise documental do PPI- IFBA. O texto está estruturado em dois momentos: (i) Reflexão sobre a concepção de Meio ambiente e Educação Ambiental e (ii) A inserção da Educação Ambiental e Meio ambiente e as questões socioambientais contidas no PPI. Espera-se com este estudo contribuir para a inserção e o desenvolvimento da Educação ambiental com vista à transformação socioambiental

\section{Reflexão sobre a concepção de Meio ambiente e Educação Ambiental}

Do mesmo modo que a Educação geral, a Educação Ambiental (EA) não pode ser vista como panaceia para todos os problemas sociais, ambientais e econômicos do planeta. Porém, deve ser vista como uma via para novos posicionamentos frente às questões ambientais. Nesse sentido, é importante fazer uma reflexão acerca da concepção de Meio Ambiente (MA), pois esta influenciará a prática do educador ambiental e na postura do indivíduo na escola, no trabalho, agricultura e lazer.

Reigota (2010) nos aponta a importância de situar a noção de M.A tanto como um conceito científico, ou seja, aquele entendido e utilizado universalmente, como uma representação social, relacionado ao senso comum. Após expor e analisar algumas 
concepções trazidas por outros estudiosos e também contidas em dicionários, o autor propõe seu próprio conceito como sendo:

[...] o lugar determinado ou percebido, onde os elementos naturais e sociais estão em relações dinâmicas e em interação. Essas relações implicam processos de criação cultural e tecnológica e processos históricos e sociais de transformação do meio natural e construído (REIGOTA, 2010, p. 13).

Em sua definição, o autor considera que meio ambiente trata de lugar determinado, pois delimita fronteiras e momentos específicos permitindo maior conhecimento; lugar percebido por estar de acordo com a visão de mundo, experiência ou da representação social de cada indivíduo; lugar com relações dinâmicas e interativas na qual o Meio Ambiente está constantemente se modificando a partir da relação dialética homem-natureza; lugar que ao mesmo tempo é transformado pelo homem como também transforma o homem.

Nesse conceito ampliado, meio ambiente é o lugar na qual ocorre a interação homem-homem e homem-natureza por meio de relações dinâmicas que se modificam. $\mathrm{O}$ homem por meio da tecnologia transforma o espaço, se transforma e transforma a natureza, e, ao mesmo tempo sua concepção de natureza. O conceito de M.A supera a ideia de espaços físicos e naturais, mas considera que nele estão inseridas as relações históricas, sociais e culturais do homem com o meio e com outros homens. Reigota aponta ainda a classificação de meio ambiente, de acordo com a Representação social dos sujeitos, como:

\footnotetext{
Naturalista - meio ambiente voltado apenas a natureza, evidencia aspectos naturais, confundindo-se com conceitos ecológicos como de ecossistema. Inclui aspectos físicoquímicos, a fauna e a flora, mas exclui o ser humano deste contexto. O ser humano é um observador externo;

Globalizante - o meio ambiente é caracterizado como as relações entre a natureza e a sociedade. Engloba aspectos naturais políticos, sociais, econômicos, filosóficos e culturais. O ser humano é compreendido como ser social que vive em comunidade; Antropocêntrica - o meio ambiente é reconhecido pelos seus recursos naturais, mas são de utilidade para a sobrevivência do homem (REIGOTA, 2010).
}

Desse modo, o educador ambiental, que tanto pode ser um professor no ensino formal, como também qualquer cidadão nos espaços informais (igrejas, clubes, empresas...), trazem suas concepções, que irão delinear a E.A de acordo com sua visão de mundo. Daí a importância da formação do sujeito para atuar em vários espaços, proporcionando uma perspectiva mais crítica da relação homem-natureza e do sistema econômico que transforma tudo em mercadoria. 
Sauvé em consonância com Reigota nos traz o meio ambiente como uma trama que envolve a natureza e a cultura, “[...] é o cadinho em que se forja nossa identidade, nossas relações com os outros, nosso ser no mundo" (SAUVÉ, 2005, p. 317). Destaca a importância de uma Educação Ambiental que induza as dinâmicas sociais por meio de uma abordagem crítica da realidade socioambiental, permitindo a compreensão dos problemas ambientais e das possibilidades de soluções, na qual o educador deve considerar as multifaces da relação homem-natureza que determinarão formas ao mesmo tempo diferentes como complementares de apreender Meio Ambiente. Assim a autora, propôs a Tipologia das Concepções sobre Meio Ambiente, sintetizado no (quadro 01), identificando as seis (06) correntes presentes na abordagem pedagógica do educador.

Quadro 01. Tipologia das Concepções sobre Meio Ambiente

\begin{tabular}{|l|l|l|}
\hline \multicolumn{1}{|c|}{ Ambiente } & \multicolumn{1}{|c|}{ Relação } & \multicolumn{1}{c|}{ Características } \\
\hline Como natureza & $\begin{array}{l}\text { Para ser apreciado e } \\
\text { preservado. }\end{array}$ & $\begin{array}{l}\text { Natureza como catedral, ou como } \\
\text { um útero, pura e original. }\end{array}$ \\
\hline Como recurso & Para ser gerenciado. & $\begin{array}{l}\text { Herança biofísica coletiva, } \\
\text { qualidade de vida. }\end{array}$ \\
\hline Como problema & Para ser resolvido. & $\begin{array}{l}\text { Enfase na poluição, deterioração e } \\
\text { ameaças. }\end{array}$ \\
\hline Como lugar para viver & $\begin{array}{l}\text { EA para, sobre e no para } \\
\text { cuidar do ambiente. }\end{array}$ & $\begin{array}{l}\text { A natureza com os seus } \\
\text { componentes sociais, históricos e } \\
\text { tecnológicos. }\end{array}$ \\
\hline Como biosfera & $\begin{array}{l}\text { Como local para ser } \\
\text { dividido. }\end{array}$ & $\begin{array}{l}\text { Espaçonave Terra, "Gaia", a } \\
\text { interdependência dos seres vivos } \\
\text { com os inanimados. }\end{array}$ \\
\hline $\begin{array}{l}\text { Como projeto } \\
\text { comunitário. }\end{array}$ & Para ser envolvido & $\begin{array}{l}\text { A natureza com foco na análise } \\
\text { crítica, na participação política da } \\
\text { comunidade. }\end{array}$ \\
\hline
\end{tabular}

Fonte: Sauvé, 2005

Sauvé (2005) chama a atenção para o fato de essas concepções existirem simultaneamente, podendo ser encontradas nas diferentes práticas educativas e nos discursos dos educadores ambientais.

A preocupação com o meio ambiente começou com um caráter preservacionista e desvinculado do espaço-meio ambiente-homem e vinculado ao papel de Estado como regulador por meio da legislação e fiscalização, porém, isto foi se modificando e se consolidou como ação modificadora de comportamentos diante dos agravos ambientais. Dentro deste contexto se encontra a Educação Ambiental construída dentro de um contexto 
histórico-social, sendo que muitos atores lutaram para a sua efetivação com vistas à transformação da relação do homem-natureza.

Dias (2000) ao trazer em seu livro a Educação Ambiental desde a década de 1960, com o lançamento do livro "Primavera Silenciosa" até o ano 2000, sob a égide da Globalização e do Neoliberalismo, nos aponta que se inicialmente as ações educativas eram na perspectiva da Ecologia, com o passar do tempo a EA toma corpo e se torna dimensão da Educação, com vistas à formação do cidadão crítico-reflexivo, considerando o meio ambiente não só como espaço físico, mas social, político e ético.

Neste sentido, destacamos três marcos importantes: (i) A Conferência de Estocolmo na Suécia em 1972 e a recomendação de um Programa Internacional de Educação Ambiental e o reconhecimento da Educação Ambiental como elemento essencial no combate à crise ambiental; (ii) A Carta de Belgrado (1975), e formulação dos princípios e orientações para a Educação Ambiental integrada, contínua e multidisciplinar; (iii) Conferência de Tbilisi, em 1977 como o primeiro evento intergovernamental em Educação Ambiental, propondo uma Educação partindo da compreensão do indivíduo acerca do meio no qual está inserido, para a prevenção e soluções dos problemas socioambientais (DIAS, 2000).

A Conferência de Estocolmo teve a marca da controvérsia quando os representantes dos países centrais culparam os países periféricos pelo aumento da degradação ambiental como consequência da tentativa do desenvolvimento econômico. A delegação do Brasil esteve à frente da resistência em defesa da industrialização e do desenvolvimento a qualquer custo, alegando que os países centrais sabotavam o crescimento econômico dos países periféricos. Assim, afrontando os representantes dos países centrais veiculou o convite para as indústrias poluentes europeias, que sofriam restrições em seus países, para se instalarem no Brasil (LIMA, 2009), resultando na abertura para as indústrias poluidoras em troca do desejado desenvolvimento econômico.

Ainda no contexto brasileiro da década de 1970, Dias (2000) aponta que existia a falta de interesse político, de um projeto educacional para o país e a manutenção da ditadura que dificultavam uma EA Crítica. O fato é que em plena Ditadura, falar em Educação emancipatória era mexer em um vespeiro, pois significava o despertar para o conhecimento, da consciência e da reflexão crítica. O conhecimento desenvolve autonomia de pensamento e de escolha, contrariando a ideologia do sistema vigente-

Carvalho (2008) analisa que na década de 1970, por pressões impostas pelas Agências Multilaterais ou, pela boa vontade daqueles engajados nas causas ambientais, o 
Brasil começava a dar os primeiros passos para a consolidação de Políticas públicas ambientais, e, em particular, em Educação Ambiental. A década de 1980 é marcada por um país com as mazelas da dívida externa, o aumento do fosso das desigualdades sociais e a mobilização da sociedade civil pela redemocratização. Foi um período fértil para os movimentos sociais em torno de melhores condições de vida, dos direitos políticos e das questões socioambientais. A promulgação da Constituição Federal de 1988 (BRASIL, 1988) traz em seu Capítulo VI, o meio ambiente como direito de todos e dever do Estado e da coletividade, assim como, a Educação Ambiental que deve ser ofertada em todos os níveis de ensino despertando a consciência para a preservação do meio ambiente.

Loureiro (2008) destaca que nos anos anteriores à promulgação da Constituição Federal de 1988, a política ambiental era de caráter tecnocrata e centralizadora, tanto nos meios governamentais quanto científicos, ainda nos moldes conservacionista e preservacionista e voltada para o estudo da ecologia. A presença de educadores adeptos da Educação emancipatória crítica e de professores militantes dos movimentos ambientalistas, propiciou a visão mais crítica dos problemas ambientais, considerando as relações sociais desiguais, o que implica em dizer que as questões ambientais não podem ser pensadas separadas das questões sociais, nos levando inferir que sem mudança social não dá para se pensar em Desenvolvimento Sustentável.

Segundo Romeiro (2012), a concepção de Desenvolvimento Sustentável surge na década de 1970, a partir do conceito de Ecodesenvolvimento e foi fruto do embate entre os países que apoiavam o desenvolvimento econômico e os que defendiam o crescimento zero, na tentativa de frear o esgotamento dos recursos naturais e a poluição e o impacto ambiental e a qualidade de vida na Terra.

Diegues (2003) aponta que o Desenvolvimento Sustentável é um conceito contido no Relatório de Brundtland, como sendo, “[...] aquele que satisfaz as necessidades do presente sem comprometer a possibilidade das gerações futuras satisfazerem as suas [...]" (DIEGUES, 2003, p. 3). O autor destaca os pontos positivos deste Relatório que trouxe elementos novos e partiu do princípio que os moldes de desenvolvimento são inviáveis, tanto para os países centrais como para os periféricos, alertando que para um projeto socioambiental que se anseia, é preciso que haja mudanças tanto sociais como econômicas, devendo para isso emergir uma nova ética. Desse modo, o Desenvolvimento Sustentável não pode ocorrer desconectado das relações sociais e do homem com a natureza, devendo ser pensado não só partindo da diversidade biológica, mas também da diversidade cultural. Nesse contexto, estão inseridas as populações tradicionais, que mantêm forte vínculo 
cultural com a sua localidade e dependem dos ecossistemas para sobreviver, ao mesmo tempo, em que são agentes de preservação e conservação do meio ambiente.

Precisamos pensar na sustentabilidade para além do Capital, que tem a natureza como mercadoria, objeto de dominação e a serviço do homem. Nesse sentido, Carvalho (2008) questiona se os mecanismos legais impostos à produção de bens, tendo como base a capacidade dos recursos naturais existentes, serão capazes de modificar a lógica do Capital e servir de freio à degradação ambiental, Alertando para o novo tipo de mercado, o mercado verde como mais uma face do Capitalismo.

Voltando às reflexões de Diegues (2003), o autor chama a atenção para o fosso da desigualdade entre os países centrais e periféricos que vem se alargando cada vez mais, sendo imprescindível se pensar sob a perspectiva das Sociedades Sustentáveis, pois o Desenvolvimento Sustentável coloca todos os países no mesmo patamar, enquanto numa Sociedade Sustentável, cada país se estruturará de acordo com suas características e tradições.

Dentro deste contexto devemos nos questionar: "Qual Educação Ambiental queremos?” e “A quem servirá esta Educação Ambiental?”. A Educação Ambiental contida em Estocolmo, 1972, como estratégia para a preservação ambiental visando à geração futura? Em Tbilisi, com o propósito de despertar a consciência das pessoas e melhorar os problemas ambientais? A Educação Ambiental permanente, articuladora de várias disciplinas e capaz de reagir frente às mudanças e com busca para a compreensão das relações entre desenvolvimento socioeconômico e a melhoria do meio ambiente?

No Capítulo 36 da Agenda 21 (BRASIL, 1995), a Educação Ambiental aparece nos termos "promoção do ensino, da conscientização e do treinamento", trazendo a importância da reorientação do ensino para o Desenvolvimento Sustentável e o aumento da conscientização, da ética, valores e de comportamento. Frisa que o ensino sobre Meio Ambiente deve ser abordado nos aspectos "do desenvolvimento físico/biológico, socioeconômico e humano" (p. 430).

Já o parágrafo $7^{\circ}$ do Art. 26 da LDB/96 (BRASIL, 2013) determina que os currículos da Educação Básica devem incluir a Educação Ambiental de forma integrada aos conteúdos obrigatórios. Sendo também reforçado na Política Nacional de Educação Ambiental, que traz a emergência para a construção de competências, habilidades e valores sociais do indivíduo e da coletividade para o cuidado com o meio ambiente. E a inserção da E.A nos currículos nas escolas públicas e privadas (Art. $9^{\circ}$ ), devendo ser contínua, 
integrada e permanente $\left(\operatorname{Art} .10^{\circ}\right)$, não podendo ser implantada como disciplina específica, mas fazer parte do currículo de formação de professores (Art. $11^{\circ}$ ).

A Educação Ambiental no Programa Nacional de Educação Ambiental - ProNEA (BRASIL, 2005) está inserida como estratégia para a promoção da articulação das ações educativas para a melhoria ambiental e a potencialização da função da Educação como agente de mudanças socioculturais, propondo práticas pedagógicas na perspectiva da transversalidade e interdisciplinaridade. Além de atrelar a Educação Ambiental à sustentabilidade socioambiental, democracia, participação social, formação de educadores e aos Projetos Políticos Pedagógicos (PPP) das instituições de ensino.

Assim como a Educação, os documentos oficiais não são neutros e trazem em si a ideologia de quem os pensam e os constroem. Devemos estar atentos aos discursos e no significado dos termos neles contidos, lembrando o que já foi posto por Silva (1996, p. 167) ao apontar as estratégias do Neoliberalismo nas transmissões das ideias, recontextualizando as categorias. O sistema hegemônico importa palavras e expressões dos movimentos sociais, que são reincorporadas, depois de serem "higienizadas", sendo muitas vezes utilizadas nos vários espaços sociais para alcançar seus objetivos.

Os documentos oficiais trazem termos como: Integração; articulação; transversalidade; interdisciplinaridade, sustentabilidade socioambiental; Desenvolvimento Sustentável, Educação permanente; formação; participação social; transformação; e, emancipação. A partir do uso destes termos, devemos refletir e novamente questionar: Estaremos realmente realizando uma Educação com vista à emancipação do indivíduo e para a transformação social, ou apenas reproduzindo as palavras vestidas de uma nova roupagem pelo sistema hegemônico?

\section{A inserção da Educação Ambiental, Meio ambiente as questões socioambientais contidas no PPI-IFBA.}

Para conhecermos a concepção de Educação Ambiental contida no PPI-IFBA foi realizada a análise documental, definida como "[...] uma operação ou um conjunto de operações visando representar o conteúdo de um documento sob uma forma diferente da original [...]" (Bardim 2009). Dessa forma, considerando o PPI-IFBA como objeto de estudo e o objetivo proposto, foram definidos os descritores investigados e em seguida realizada a leitura preliminar e posteriormente a exploração do material, a inferência e 
interpretação para a melhor compreensão da realidade. Para tanto, os descritores relacionados com a temática estão destacados em negrito.

Considerando que o IFBA oferta cursos na Educação básica profissional na modalidade de ensino médio integrado e subsequente e Educação superior (bacharelado, licenciatura e tecnólogo), o PPI é o documento que define a linha pedagógica a ser seguida e qual o projeto de Educação pensado pelo instituto. Neste sentido, Veiga (2002) analisa que o projeto pedagógico é uma visão do futuro e reflete o anseio da comunidade para além do plano de ensino e atividades da escola, ou um amontoado de documentos burocráticos, devendo ser não só construído, mas vivenciado por todos.

Neste sentido, é importante analisarmos qual a filosofia de Educação proposta no PPI do IFBA e a inserção da Educação Ambiental e a temática meio ambiente no referido documento, partindo do pressuposto que nele está definindo a finalidade, a concepção de sociedade e o tipo de formação pretendida.

Assim, numa primeira análise a perspectiva de Educação Ambiental começa dar seus primeiros indícios ao lermos o ideário de formação que o IFBA almeja contido na definição de sua Missão, qual seja: "Promover a formação cidadão histórico-crítico, oferecendo ensino, pesquisa e extensão com qualidade socialmente referenciada, objetivando o Desenvolvimento Sustentável do país" (PP I-IFBA, 2013, p. 27). O termo em destaque cria a expectativa de uma formação com vistas às questões socioambientais por estar embasado na Práxis da Pedagogia Histórico-Crítica, que tem como referência Dermeval Saviani, quando aponta que:

[...] Nessa formação a educação é entendida como mediação no seio da prática social global. A prática social se põe, portanto como ponto de partida e o ponto de chegada da prática educativa [...] (SAVIANI, 2005, p. 26).

O PPI-IFBA propõe assim, a formação do sujeito capaz de conhecer, refletir e intervir na sociedade reconhecendo-se como ser histórico que transforma e é transformado pela sociedade e, ao mesmo tempo, tem consciência do seu papel transformador da sociedade. Desse modo, o Instituto se compromete com a formação para além da dimensão técnica com vistas ao mercado de trabalho, mas na perspectiva da dimensão política, ética e humana.

No processo de construção do PPI, o Instituto partiu das demandas da sociedade, da reflexão crítica da realidade do país e da Educação profissional e ainda, dos debates com a comunidade escolar local, assumindo a (i) igualdade e solidariedade; (ii) a equidade; (iii) a 
inclusão; (iv) a democracia e (v) a sustentabilidade como princípio de promoção humana e das suas relações com a sociedade e a natureza, como princípios que serviriam como referências das relações sociais, administrativas e educativas, destacando na página 20: “[...] Esses princípios se justificam na perspectiva de formação de um sujeito omnilateral $[\ldots]$ ", ou seja, para o desenvolvimento pleno do sujeito, tendo o Trabalho como princípio educativo. Desse modo, vislumbramos mais uma vez a possibilidade da Educação Ambiental ocupar espaço no PPI-IFBA.

No item que trata da Finalidade/Objetivos do IFBA o documento aponta entre eles: "[...] promover a produção, o desenvolvimento e a transferência de tecnologias sociais, notadamente as voltadas à preservação do Meio Ambiente” (p. 29), evidenciando o caráter técnico científico de suas ações a partir da concepção de meio ambiente como recurso.

Na Dimensão II ao definir os Princípios filosóficos e teórico-metodológicos gerais que norteiam as práticas educativas da Instituição (p.33), o documento destaca as mudanças sociais, ambientais e do trabalho que exigem uma formação profissional como um processo de construção social superando, dessa forma, a formação do trabalhador apenas para a execução da técnica, mas para a compreensão da tecnologia como resultado da produção do ser social. Assim, o IFBA reforça a preocupação com a formação integral do sujeito, trazendo novas expectativas para a Educação Ambiental como um projeto de Educação do Instituto.

Ainda na Dimensão II, o documento reconhece a necessidade da formação profissional sustentável, tendo a Educação como referência para formação geral com vistas à formação integral, considerando os desafios sociais, econômicos e ambientais da atualidade, apontando a Educação como responsável para a formação ética e solidária. Diz essa dimensão que:

O comportamento solidário e inclusivo exige atenção com o Meio Ambiente, isto é, a sustentabilidade passa necessariamente por um ambiente saudável e a preservação dos materiais, insumos, e componentes retirados da natureza e presentes na nossa realidade na forma de energia, espaços físicos e equipamentos que usamos no dia a dia, exige a devida atenção ao seu desgaste. A formação de um cidadão que incorpore a profissionalização sustentável deve ser construída cotidianamente com a assunção das responsabilidades individuais e coletivas de cada professor (a), técnico (a), estudante (PPI-IFBA, 2013, p. 35). 
Aqui também, sobre o viés da sustentabilidade e da preservação, o meio ambiente aparece como um recurso, causando um estranhamento, posto que frente à crise ambiental, a EA não pode ser limitada às visões e ações também reducionistas e fragmentadas de meio ambiente como exposto no trecho acima, contradizendo a proposta de formação para a compreensão e a criticidade para atuar no mundo.

No que tange às questões ambientais, elas só se apresentam com ênfase na Dimensão Político-pedagógica, especificamente no item 11, que trata da Responsabilidade socioambiental do IFBA e o seu papel fomentador de inclusão socioambiental. O documento faz a contextualização conceitual e histórica do Desenvolvimento Sustentável, apresenta as questões socioambientais relacionadas com a urbanização, faz o resgate histórico das Políticas públicas ambientais e chama a atenção para os três pilares que compõem a sustentabilidade (social, econômica e ambiental), afirmando que:

[...] não se pode pensar em sustentabilidade apenas através da preservação do Meio Ambiente, visto que as sociedades dependem social e economicamente deste. Assim sendo, a sustentabilidade não pode ser vista apenas sob o ponto de vista ambiental e praticada apenas por profissionais da área; "todos têm direito a um Meio Ambiente ecologicamente equilibrado, impondo-se ao poder público e à coletividade o dever de defendê-lo e preservá-lo para as presentes e futuras gerações" (artigo 225 da Constituição de 1988) - deve-se entender Meio Ambiente como o espaço, não necessariamente natural, de interação de espécies (humanas e não humanas) entre si e com o meio, passível de modificações (PPI-IFBA, 2013,p. 88).

Este trecho é contraditório, pois inicialmente aponta a concepção de meio ambiente sob o paradigma neoliberal de Desenvolvimento Sustentável, na qual o meio ambiente deve ser poupado e não questiona o modelo predatório da produção de bens. Por outro lado, traz elementos que evidenciam a concepção de meio ambiente proposto por Reigota (2010), como o lugar no qual ocorre a interação homem-homem e homem-natureza, permeada por relações dinâmicas nas quais o homem por meio da tecnologia transforma o espaço, transforma a si mesmo, a natureza e, ao mesmo tempo, sua concepção de natureza, assumindo o conceito ampliado de meio ambiente para além dos aspectos físicos e naturais.

Não obstante, o elencar o que deverá ser realizado pelo IFBA, o PPI aponta principalmente medidas na perspectiva preservacionista e conservacionista, sendo que apenas um item diz respeito à possibilidade de uma Educação ambiental crítica como destacado: “[...] Incorporação e adequação da temática ambiental à realidade de cada disciplina do currículo escolar como proposta educacional contextual e emancipatória 
[ ]” (PPI-IFBA, 2013, p 89). Este trecho reforça o que o IFBA propõe em sua Missão, mas ainda mantém uma postura voltada para ações conservadoras e tradicionais que não questionam um sistema econômico que transforma homem e natureza em mercadorias.

Ao trazer no documento a Responsabilidade Socioambiental, o Instituto busca atender o que determina a Agenda Ambiental na Administração Pública com vistas à implantação de ações e práticas sustentáveis tendo como base os (05) eixos temáticos prioritários: (i) pelo uso racional dos recursos naturais: (ii) gestão de resíduos; (iii) qualidade de vida no ambiente do trabalho; (iv) sensibilização e capacitação dos servidores e (v) licitações sustentáveis (BRASIL-MMA, 2009, p. 36), por meio de uma proposta para mudanças de atitudes e comportamentos.

Seguindo a análise ainda dentro do tópico Responsabilidade socioambiental, o documento ressalta a importância da escola como espaço para práticas sustentáveis, a formação crítica e a inserção das questões ambientais à Educação. Diz o documento:

No ambiente escolar, as ações de posturas sustentáveis e o estímulo a suas práticas se configuram em práticas de responsabilidade social, que se estendem à formação de indivíduos críticos e formadores de opinião, capazes de interagir com as questões ambientais, sociais e econômicas de forma responsável, ética e justa. Através da inserção das dimensões ambiental e social ao processo educacional, a escola forma cidadãos, contribui com o desenvolvimento do país e atua em consonância com a Lei de Diretrizes e Bases da Educação Nacional (9394 2 Lei): "é de responsabilidade da escola, fornecer uma educação que objetive o pleno desenvolvimento do educando, o seu preparo para o exercício da cidadania e sua qualificação para o trabalho" (PPI-IFBA, 2013, p. 88).

Entre o discurso realizado no trecho acima e as ações propostas pelo IFBA na página 89, existe um grande hiato. Para melhor entendimento, após analisar o grupo de ações propostas, buscamos separá-las em três subgrupos: de cunho pedagógico; de gestão ambiental e social.

As ações de cunho pedagógico estão voltadas para a formação dos sujeitos, como explicitado no trecho “[...] Incorporação e adequação da temática ambiental à realidade de cada disciplina do currículo escolar como proposta educacional contextual e emancipatória (PPI-IFBA, 2013, p. 89)". A parte do texto em negrito nos aponta para a intenção da inserção da Educação Ambiental emancipatória, crítica e transformadora como colocado por Layrargues:

A Educação Emancipatória se conjuga a partir de uma matriz que compreende a educação como elemento de transformação social inspirada no diálogo, no exercício da cidadania, no fortalecimento dos sujeitos, na 
criação de espaços coletivos de estabelecimento de convívio social, na superação das formas de dominação capitalistas, na compreensão do mundo em sua complexidade e da vida em sua totalidade. Como Práxis social que contribui no processo de construção de uma sociedade pautada por novos padrões civilizatórios e societários distintos dos atuais, na qual a sustentabilidade da vida, a atuação política consciente e a construção de uma ética se firme como ecológica sejam seu cerne. Educar é emancipar (LAYRARGUES, 2012, p. 17).

Por outro lado, a outra ação proposta como cunho pedagógico nos traz:

Orientar os servidores e estudantes sobre práticas cidadãs e ambientalmente sustentáveis - éticas, economia solidária, redução das desigualdades sociais, respeito às diversidades, entre outras -, despertando a corresponsabilidade de todos no estabelecimento de um ambiente mais agradável, limpo, salubre, despoluído e descontaminado (PPI-IFBA, 2013, p. 89).

O trecho em destaque nos dá a ideia de contradição em relação à ação anterior que clama por uma formação emancipatória. Ao apontar para uma ação pautada na orientação nos remete à ideia de "Educação" informativa, seguindo os moldes da Educação Ambiental conservadora, bancária que não possibilita a troca e nem a construção coletiva do conhecimento para a transformação do sujeito e do meio onde está inserido. Isso nos remete a Loureiro, ao nos falar que a atuação da Educação Ambiental está para além do plano das ideias e da transmissão de conteúdos informativos, mas está voltado para o campo da existência e da consciência, em que conscientizar não é dádiva do educador para aquele que "aprende", sendo, sobretudo, um processo caracterizado "[...] pela ação com conhecimento, pela capacidade de fazermos opções e termos compromisso com o outro e com a vida [...]” (LOUREIRO, 2012, p. 33), superando o orientar e o adestrar.

No que se refere às ações de cunho de gestão ambiental, elas são as que mais estão presentes no rol das ações que o IFBA pretende desenvolver para se tornar responsável socioambiental, como demonstram alguns trechos selecionados:

Otimizar atividades que façam uso racional e equitativo dos recursos naturais;

Estimular a redução do desperdício de água em banheiros, cantinas, restaurantes, através da instalação de temporizadores nas torneiras;

Estimular a redução do desperdício de água em todos os setores através da instalação de tanques coletores da água descartada pelas torneiras para seu reaproveitamento em atividades de jardinagem [...] (PPI-IFBA, 2013, p. 89). 
Esse trecho também evidencia a preocupação para preservação do recurso natural como um bem precioso com vistas à geração futura. Reconhecemos a relevância dessas ações, porém, elas devem ser problematizadas, instigando a comunidade IFBA à reflexão crítica das relações de poder contidas no sistema econômico e nas relações do homem, do seu papel de agente de mudança social e da alteridade.

No que tange às ações de cunho social elencadas no documento, estas demonstram o rumo da relação homem-natureza que o Instituto diz que almeja, embora elas representem apenas em três das 21 ações propostas, como descrito a seguir:

\section{$[\ldots]$}

Garantir a preservação das características culturais regionais;

Apoiar o desenvolvimento socioeconômico da comunidade, através do processo de ensino, de projetos e pesquisa e extensão, bem como de campanhas solidárias;

Estimular o envolvimento de estudantes e funcionários com as questões socioeconômicas da comunidade (PPI-IFBA, 2013, p. 90).

$[\ldots]$

Assim, nos trechos a cima destacados vislumbramos a possibilidade da Educação Ambiental para além da a preservação do meio ambiente, como nos fala Diegues (2003) ao apontar que o Desenvolvimento Sustentável não pode ocorrer desconectado das relações sociais e da relação do homem com a natureza, considerando também a diversidade cultural e as populações tradicionais que possuem vínculos culturais com o meio ambiente e dele dependem. Nesse sentido, "Ensino, Pesquisa e Extensão", articulados e integrados possibilitam a aproximação com a comunidade na qual o Instituto está inserido, conhecendo a realidade local, seus anseios, propondo e desenvolvendo ações transformadoras.

No que se refere ao descritor "Educação Ambiental", constatamos que este aparece apenas cinco vezes em todo o documento, iniciando na página 88 , ao se fazer a introdução sobre a Responsabilidade Socioambiental do IFBA ao apontar, entre outros fatores, a falta da Educação Ambiental diante do crescimento urbano desordenado, a degradação ambiental e os problemas socioeconômicos atrelados às questões socioambientais. Mais adiante, na página 93, nos itens cinco e seis, uma nova referência demonstrando a preocupação com o desperdício da água e de energia elétrica, propondo ações para a resolução dos problemas, afirmando que:

Nos novos projetos de edificação, reforma e ampliação, propor a utilização de tecnologias que permitam empregar a gestão integrada da água, com a implementação de sistemas para a redução do consumo de 
água e seu reaproveitamento. Além disso, devem ser trabalhadas, no campo da Educação Ambiental, práticas visando o controle do desperdício de água.

Nos novos projetos de edificação, reforma e ampliação, propor a utilização de energias alternativas com a substituição de energias não renováveis pelas renováveis, além de soluções que empreguem o bioclimatismo. Devem ser trabalhadas, ainda, no campo da Educação Ambiental, práticas visando o controle do desperdício de energia (PPI-IFBA, 2013.)

Nos campos em destaque o documento, mais uma vez, demonstra a falta de clareza sobre a concepção que o Instituto tem de Educação Ambiental, reduzindo-a em ações fragmentadas, pontuais e descontextualizadas. Este "equívoco" do que é Educação Ambiental se repete na página 94, quando de forma reducionista propõe a Educação Ambiental como treinamento voltado para os 3Rs (Redução, Reutilização e Reciclagem) dos resíduos (lixos). “[...] Promover treinamento sobre educação ambiental para prestadores de serviços de manutenção técnica, de limpeza, de copa e outros [ ]" (PPIIFBA, 2013p.94). Assim, torna-se importante recorrer à reflexão de Loureiro ao pontar que:

A Educação Ambiental não é adestramento e transmissão de informações. Ela atua no campo da existência, na qual o conscientizar está relacionado à ação com conhecimento. O conhecimento nos dá autonomia e o poder e de fazermos escolhas (LOUREIRO, 2012, p. 33).

Uma escola que tem como base a Práxis da Pedagogia Histórico-Crítica deve repensar a proposta de ações pedagógicas tecnicistas em Educação Ambiental voltadas à “[...] aquisição de habilidades, atitudes e conhecimentos específicos, úteis e necessários para que os indivíduos se integrem na máquina do sistema social global [...]" (LIBÂNEO, 2005, p. 28).

Por último, a Educação Ambiental aparece como potencialidade nas Diretrizes para a Educação Profissional Técnica de Nível Médio (EPTNM) contidas no PPI, buscando maior integração com a comunidade e superando a visão da escola como uma ilha.

Instituir um programa de integração escola-comunidade (escola aberta), com oferta de cursos, palestras e atividades socioculturais, artísticas e desportivas, educação ambiental e atendimento a outras demandas identificadas junto à comunidade (PPI-IFBA, 2013, p. 105).

A mesma Diretriz aponta para a abordagem interdisciplinar dos temas ambientais, assim como outros temas que não estejam contemplados nas disciplinas da Base Comum, como exposto no trecho: “[...] Articular, por meio de uma metodologia interdisciplinar, 
eixos que estão contemplados nos PCNs como: Meio Ambiente, sexualidade, gênero, drogas, entre outros relevantes para a sociedade" [ ] (PPI-IFBA, 2013, p. 105).

Da mesma forma, as Diretrizes Curriculares Nacionais para o Ensino Médio (DCNEM, 2012) corroboram com o PCN e, ao tratar sobre o Projeto Pedagógico, destaca no Art.16 que as escolas devem abordar outras temáticas para o desenvolvimento pleno do sujeito, apontando entre outros:

I - atividades integradoras artístico-culturais, tecnológicas e de iniciação científica, vinculadas ao trabalho, ao Meio Ambiente e à prática social:

XVII - estudo e desenvolvimento de atividades socioambientais, conduzindo a Educação Ambiental como uma prática educativa integrada, contínua e permanente; [...] (DCNEM, 2012, p. 6).

Ainda de acordo com a DCNEM (2012), o Art. 10 determina que os temas com legislação específica, como a Educação Ambiental deve ser abordado na perspectiva transversal e integral e permeando o currículo.

Retornando à análise do PPI-IFBA, o documento ao destacar a articulação curricular, aponta sua importância na formação integral, possibilitando ao estudante estabelecer melhor relação entre os conhecimentos adquiridos, a visão crítica e a construção de novos saberes. Divide, assim, a articulação curricular em (02) eixos: o primeiro está direcionado para a abordagem multidisciplinar, interdisciplinar e transdisciplinar das disciplinas. O segundo eixo é composto pelos conteúdos culturais e esportivos e não há referência às questões ambientais e Educação Ambiental. Daí a importância da comunidade IFBA compreender como a Educação Ambiental está inserida no Projeto Pedagógico de Curso (PPC) tanto na Educação Profissional Técnica de Nível Médio (EPTNM), como na Educação superior e na pós-graduação, como expresso em sua concepção de currículo e de práticas para a formação integral dos sujeitos.

[...] o currículo como um conjunto de formulações (representações, saberes, programas, disciplinas, estruturas) e de experiências (atividades, práticas, vivências) propiciados pela instituição de ensino para a formação dos sujeitos, de acordo com as grandes finalidades a que se propõe (Vasconcellos, pp. 28, 2011), então a arquitetura curricular aqui diz respeito ao desenho e à articulação das diversas áreas de conhecimento, numa concepção integradora e interdisciplinar e numa perspectiva do sujeito histórico-crítico (PPI-IFBA, 2013, p. 94). 
Os campos em destaque nos fazem retornar à proposta de articulação curricular descrito no documento, que se revela como uma inovação, apontando práticas pedagógicas na proposta interdisciplinar e transdisciplinar, superando a multidisciplinaridade como metodologia nas práticas educativas próprias da Educação tradicional, refletindo nas práticas docentes e do estudante como educador ambiental.

Finalizando essa análise documental, o PPI-IFBA toma o Trabalho como princípio educativo, nos lembrando da proposta de formação do sujeito crítico capaz de refletir e compreender o mundo à sua volta e nele atuar por meio do trabalho, transformando-se e, ao mesmo tempo, transformando suas relações sociais e com a natureza. Assim, entre os princípios que estabelece para a EPTNM propõe:

I - relação e articulação entre a formação desenvolvida no Ensino Médio e a preparação para o exercício das profissões técnicas, visando à formação integral do estudante;

\section{$[\ldots]$}

III - trabalho assumido como princípio educativo, tendo sua integração com a ciência, a tecnologia e a cultura como base da proposta político-pedagógica e do desenvolvimento curricular (PPIIFBA, 2013).

O IFBA considera o princípio educativo do trabalho não apenas como metodologia para o processo ensino-aprendizagem, mas na sua dimensão ético-política, possibilitando a formação emancipatória e a criticidade. Uma formação que não seja apenas voltada para atuar no mercado de trabalho, mas para a atuação no mundo, que vai além da atividade laboral e se estende às produções sociais relacionadas ao trabalho. Um mundo que é envolvido pelas dimensões biológicas, culturais, sociais, éticas, políticas e econômicas, e que se reconfigura histórica e socialmente.

Dessa forma, tendo o trabalho na sua concepção filosófica é possível torná-lo fio condutor para superar as práticas educativas cartesianas, estabelecendo diálogo com as várias áreas de conhecimento contidas na matriz curricular e com os demais cursos oferecidos pelo Instituto. Nesse sentido, a Educação Ambiental que permeia a dimensão social, cultural, ética e política da vida humana, pode ser o elemento integrador entre as disciplinas, proporcionando a troca de saberes, diálogo e a construção de uma aprendizagem significativa para atuar diante da degradação ambiental e das desigualdades sociais. 


\section{Considerações}

Diante da crise ambiental na atualidade e, ao mesmo tempo, o movimento do Capital para minimizá-la e até negá-la, as instuiçoes de ensino como o IFBA devem cada vez mais se posionarem para a formação de sujeitos para a interveção nessa realidade, pois como nos disse Gadotti anteriormente, o planeta não aguentará tamanha agressão e a vida está comprometida. Uma crise ambiental agravada por um modelo econômico onde tudo vira mercadoria, destruindo os recursos naturais e perpetuando as desigualdades sociais.

Desse modo, a Educação Ambiental como prática social se torna estratégia para a construção de conhecimentos, valores, atitudes e o desenvolvimento de uma nova postura frente às questões socioambientais. Ao desconsiderar a complexidade das questões ambientais, vendo a realidade socioambiental por uma fresta e que não possibilita a compreensão em sua totalidade, rejeitarmos o caráter histórico-social da relação homemnatureza, o modo de produção de nossa vida, a crise ambiental e negamos a Educação no seu sentido mais amplo, que é formação integral. O instituto é um espaço privilegiado para a Educação Ambiental que supere a concepção ingênua sobre a degradação ambiental, para uma concepção crítica, considerando o meio ambiente em sua totalidade.

Ao percorremos o caminho para compreendermos o lugar da Educação Ambiental no PPI- IFBA, evidenciamos que o descritor Educação Ambiental aparece de forma tímida e não há uma proposta clara para sua efetivação, estando presente principalmente no item que trata da Responsabilidade socioambiental do Instituto, sob o viés da Gestão ambiental e de caráter conservacionista/recursista, tendo a Educação como orientação e treinamento, contrapondo a formação ominilateral proposta em sua Missão. O descritor Meio Ambiente se apresenta no documento de forma fragmentada de caráter recursista e preservacionista, desconsiderando as relações históricas e sociais do homem - natureza e do homem-homem.

\section{Referências}

BAHIA [(PPI-IFBA 2013)]. Instituto Federal de Educação, Ciência e Tecnologia da Bahia Projeto Pedagógico Institucional do IFBA. Salvador, 2013. Disponível em: https://portal.ifba.edu.br/proen/PPIIFBA.pdf. Acesso em: $20 \mathrm{de} \mathrm{dez.} 2019$

BARDIN, Laurence. Análise de Conteúdo. Portugal: Editora 70, 2009. 
BRASIL. Lei de Diretrizes e Bases da Educação Nacional: Lei no 9.394, de 20 de dezembro de 1996, que estabelece as Diretrizes e Bases da Educação nacional. e.8. Brasília: Câmara dos Deputados, Edições Câmara, 2013.

BRASIL. Programa Nacional de Educação Ambiental (ProNEA). Ministério do Meio Ambiente e Ministério da Educação. Brasília: 2005.

BRASIL. Conferência das Nações Unidas sobre o Meio Ambiente e Desenvolvimento: de acordo com a Resolução. JP! 44/228 da Assembleia Geral da ONU, de 22-12-89, estabelece uma abordagem equilibrada e integrada das questões relativas a Meio Ambiente e desenvolvimento: a Agenda 21 - Brasília: Câmara dos Deputados, Coordenação de Publicações, 1995.

BRASIL. Lei 9.795, de 27 de Abril de 1999. Dispõe sobre a Política Nacional de Educação Ambiental. Brasília: 1999. Disponível em: < https://www.mma.gov.br . Acesso em: 22 dez.2015.

BRASIL. Resolução n ${ }^{\circ}$ 2, de 30 de Janeiro 2012. Define as Diretrizes Curriculares Nacionais para o Ensino Médio. Ministério da Educação. Brasília, 2012. Disponível em:< http://portal.mec.gov.br>. Acesso em: 22 dez.2019.

BRASIL. Constituição Federal de 1988. 53 ed. Atualizada. Brasília: 2016. Disponível em:

https://www2.senado.leg.br/bdsf/bitstream/handle/id/518231/CF88_Livro_EC91_2016.pdf Acesso em: 24 dez.2019

CARVALHO, Isabel Cristina de Moura. A Educação Ambiental no Brasil. In: BRASIL, TV Escola. Programa Salto para o Futuro. Educação Ambiental no Brasil. Ministério da Educação. Brasília, 2008. Disponível em:< http://cdnbi.tvescola.org.br/resources/VMSResources/contents/document/publicationsSerie s/164816Educambiental-br.pdf $>$. Acesso em: 30 dez.2019

DIAS, Genebaldo Freire. Educação Ambiental. Princípios e práticas. 6. ed. Revisada e ampliada. São Paulo: Gaia, 2000.

DIEGUES, Antônio Carlos. Sociedades sustentáveis. Universidade de São Paulo. São Paulo: 2003. Disponível em: <http://nupaub.fflch.usp. br/sites/nupaub.fflch.usp. br/files/color/comsust >. Acesso em: 20 dez.2019

GADOTTI, Moacir. Pedagogia da terra e cultura de sustentabilidade. Revista Lusófona de Educação, n.6, 2005. Universidade Lusófona de Humanidades e Tecnologias de Portugal. Disponível em:<http://revistas.ulusofona.pt/index.php/rleducacao/article1 > Acesso em: 20 dez.2019.

LAYRARGUES, Philippe Pomier. Para que a educação ambiental encontre a educação. In: LOUREIRO, Carlo Federico Bernardo. Trajetória e fundamentos da educação ambiental. 4. ed. São Paulo: Cortez, 2012.

LIBÂNEO, José Carlos. Democratização da Escola pública. A pedagogia crítico-social dos conteúdos. e.9. São Paulo: edições Loyola, 2005. 
LIMA, Gustavo Ferreira da Costa. Educação ambiental crítica: do socioambientalismo às sociedades sustentáveis. Educação e Pesquisa, São Paulo, v.35, n.1, p. 145-163, jan./abr. 2009. Disponível em: http://www.scielo.br/pdf/ep/v35n1/a10v35n1.pdf. Acesso em: 20 dez.2019.

LOUREIRO, Carlos Frederico Bernardo. Aspectos históricos e pedagógicos da Educação Ambiental no Brasil. In: BRASIL, TV Escola. Programa Salto para o futuro. Educação Ambiental no Brasil. Ministério da Educação. Brasília, 2008.

LOUREIRO, Carlos Frederico Bernardo. Fundamentos da Educação Ambiental. In: LOUREIRO, Carlos Frederico B. Trajetória e Fundamentos da Educação Ambiental.4.e. São Paulo: Cortez editora, 2012.

REIGOTA, Marcos. Meio Ambiente e representação social. 3. e. São Paulo: Cortez, 2010 .

ROMEIRO, Ademar Ribeiro. Desenvolvimento sustentável :uma perspectiva econômico ecológica. Revista Estudos Avançados .v.26, n.74. São Paulo, 2012. Disponível em < http://www.scielo.br/pdf/ea/v26n74/a06v26n74.pdf>. Acesso em :22 dez.2019.

SAUVÉ, Lucie. Educação Ambiental: possibilidades e limitações. Revista Educação e Pesquisa. São Paulo, v 31,n.2, p. 317-322, maio/ago. 2005. Disponível em:< www.scielo.br/pdf/ep/v31n2/a12v31n2.pdf> Acesso em: 20 dez.2019

SAVIANI, Dermival. Educação: do senso comum à consciência filosófica. São Paulo: Editora Autores Associados, 1982.

SAVIANI, Dermival. Sobre a natureza e a especificidade da Educação. In: SAVIANI, Demival Pedagogia Histórico-Crítica. 9 ed. Campinas, São Paulo: Autores Associados, 2005

SILVA, Tomaz Tadeu. O projeto educacional da nova direita e a retórica da qualidade total. In: Silva, Tomaz Tadeu; GENTILLI, Pablo (org). Escola S.A: quem ganha e quem perde no mercado educacional do neoliberalismo. Brasília: CNTE, 1996.

VEIGA, Ilma Passos Alencastro. (org) Projeto político: pedagógico da escola: uma construção possível.14 ${ }^{a}$ edição Papirus, 2002. 